\title{
PENGARUH PENGAWASAN, AKUNTABILITAS DAN TRANSPARANSI KEUANGAN TERHADAP KINERJA PEGAWAI (STUDI KASUS PADA DINAS PERHUBUNGAN KOTA TIDORE KEPULAUAN)
}

\author{
Erick Try Putra Benawan ${ }^{1}$, David P.E Saerang ${ }^{2}$, Winston Pontoh ${ }^{3}$ \\ 1,2,3 Jurusan Akuntansi, Fakultas Ekonomi dan Bisnis, Universitas Sam Ratulangi, Jl. Kampus Bahu, Manado, \\ 95115, Indonesia
}

E-mail : erick.tryputrabenawan@yahoo.com

\begin{abstract}
This research aims to know (1) the supervision of the financial influence on performance the employees, (2) Financial accountability against the influence of the performance of the employees, (3) to know how the transparency of financialmagainst the performance of the employees, and (4) the influence of supervision, accountability and transparency of financial performance against employees. This research was carried out at the Department of transportation of the city of Tidore Islands with a total population of as many as 30 people. The technique of sampling the Sampling technique using Saturated where the entire population was used as a sample to the population of less than 30 people. Types of data used in the study is quantitative data types and data sources while the primary data source. Method of data collection is done using documentation and detailed questionnaire. Data analysis techniques using multiple linear regression analysis with the help of the program SPSS version 16.00. The results of this study suggest that (1) the supervision of the influential Financial significantly to the performance of the employees of the Department of transportation of the city of Tidore Islands, (2) significant influential financial accountability against staff performance Department of transportation city of Tidore Islands, (3) transparency of financial no effect significantly to the performance of the City Department of Transportation employee Tidore Islands.
\end{abstract}

Keywords: Supervision, Accountability, Transparency, Employee Performance.

\section{PENDAHULUAN}

Suatu instansi pemerintah sangat erat kaitannya dengan pengawasan dan transparansi. Pengawasan terhadap keuangan di suatu instansi pemerintah juga sangat penting dilakukan, karena Pengawasan merupakan tindakan nyata dan paling efektif dalam mewujudkan kedisiplinan pegawai organisasi (Hasibuan, 2009). Selanjutnya Hasibuan (2009) menyatakan bahwa faktor- faktor yang mempengaruhi disiplin kerja seorang pegawai adalah tujuan dan kemampuan, teladan pimpinan, balas jasa, keadilan, pengawasan melekat, sangsi hukum dan ketegasan. Pengawasan merupakan hal yang sangat penting dalam setiap pekerjaan. Sebab dengan adanya pengawasan yang baik maka sesuatu pekerjaan akan dapat berjalan lancar dan dapat menghasilkan suatu hasil kerja yang optimal. Semakin lancar kerja dan disertai pengawasan yang baik maka pekerjaan itu akan berhasil dengan baik. Dengan pengawasan yang baik akan mendorong pegawai lebih giat dalam bekerja dan menghasilkan kerja yang baik pula terlebih apabila menyelesaikan pekerjaannya dengan semangat yang baik.

Di satu sisi akuntabilitas sangat diperlukan sebagai bentuk pertanggung jawaban pemerintah kepada masyarakat. Akuntabilitas publik adalah prinsip pertanggungjawaban publik yang berarti bahwa proses penganggaran mulai dari perencanaan, penyusunan dan pelaksanaan harus benar-benar dilaporkan dan dipertanggungjawabkan kepada DPRD dan masyarakat. Salah satu prinsip keuangan daerah yaitu akuntabilitas. Akuntabilitas mensyaratkan bahwa pengambilan keputusan berprilaku sesuai dengan mandat yang diterimanya. Aspek penting yang harus dipertimbangkan yaitu: 1) aspek legalitas penerimaan 
dan pengeluaran daerah bahwa setiap transaksi yang dilakukan harus dapat dilacak otoritas legalnya, 2) aspek pengelolaan (sterwarship) keuangan daerah secara abik, perlindungan asset fisik dan finansial mencegah terjadinya pemborosan dan salah urus. Untuk ini, perumusan kebijakan, bersama-sama dengan cara dan hasil kebijakan tersebut harus dapat diakses dan dikomunikasikan secara vertikal maupun horizontal dengan baik (Mardiasmo, 2016).

Selain pengawasan dan akuntabilitas dalam suatu instansi juga harus bersifat transparan atau terbuka. Keuangan dan pembiayaan merupakan bagian yang tidak dapat terpisahkan dalam suatu manajemen instansi pemerintah. Dengan kata lain, mengingat setiap kegiatan memerlukan biaya, komponen keuangan dan pembiayaan ini perlu dikelola secara lebih efektif, efisien, dan transparan agar dana yang ada dapat menunjang tercapainya tujuan dalam kegiatan yang akan dilaksanakan.

Pengawasan, akuntabilitas dan transparansi keuangan terhadap kinerja pegawai di Dinas perhubungan Kota Tidore Kepulauan adalah untuk mengetahui apakah pelaksanaan suatu pekerjaan atau kegiatan keuangan sudah dilakukan sesuai rencana aturan dan tujuan yang telah di tetapkan secara transparansi yakni adanya kebijakan terbuka bagi pengawasan dan pertanggung jawaban terhadap kinerja pegawai. Keuangan pada Dinas Perhubungan Kota Tidore Kepulauan ini juga dapat di ukur dengan gaji/upah para tenaga kerja honorer di dinas perhubungan yang dapat dikatakan tidak terhambat atau tepat waktu. jika dibandingkan dengan instansi pemerintah lainnya.Namun salah satu kekurangan Dinas Perhubungan Kota Tidore Kepulauan tidak memiliki website untuk bisa di jangkau oleh masyarakat luas.

Pengawasan,akuntabilitas dan transparasi keuangan harus di tunjukan kepada pegawai agar kinerja pegawai bisa stabil dan konsisten. Kinerja pegawai adalah kesediaan seseorang atau sekelompok orang untuk melakukan sesuatu kegiatan dan menyempurnakannya sesuai dengan tanggung jawabnya dengan hasil seperti yang diharapkan. Performance atau kinerja adalah hasil kerja yang dapat dicapai oleh seseorang dalam suatu instansi pemerintah sesuai dengan wewenang dan tanggung jawab masing-masing dalam upaya pencapaian tujuan instansi pemerintah secara legal, tidak melanggar hukum dan tidak bertentangan dengan moral atau etika.

\section{TINJAUAN PUSTAKA}

\subsection{Akuntansi Pemerintahan}

Akuntansi Pemerintah ( Govermental accounting ), adalah yang berhubungan dengan pencatatan dan pelaporan transaksi ekonomi di lembaga- lembaga pemerintah. Pencatatan itu mencakup administrasi keuangan negara, pelaporan, dan pengontrolan anggaran tidak terjadi penyimpangan dari undang-undang dan peraturan yang berlaku.

\subsection{Pengawasan}

Pengawasan merupakan sebuah proses di dalam menetapkan ukuran dari kinerja dan juga pengambilan tindakan yang dapat mendukung dalam pencapaian hasil yang diharapkan agar sesuai dengan kinerja yang sudah ditetapkan. Atau juga dapat diartikan ialah sebuah proses agar dapat memastikan bahwa segala aktivitas yang terlaksana sesuai seperti apa yang sudah direncanakan.

\subsection{Tujuan Pengawasan}

Siswandi (2009 : 83-84) mengatakan bahwa tujuan pengawasan adalah :

a. Pengukuran kepatuhan terhadap kebijakan, rencana, prosedur, peraturan dan hukum yang berlaku

b. Menjaga sumber daya yang dimiliki organisasi

c. Pencapaian tujuan dan sasaran yang yang telah ditetapkan oleh organisasi

d. Dipercayainya informasi dan keterpaduan informasi yang ada di dalam organisasi

e. Kinerja yang sedang berlangsung dan kemudian membandingkan kinerja 
aktual dengan standar serta menetapkan tingkat penyimpangan yang

kemudian mencari solusi yang tepat.

\subsection{Akuntabilitas}

Akuntabilitas adalah kewajiban agen (pemerintah) untuk mengelola sumber daya, melaporkan, dan mengungkapkan segala aktivitas dan kegiatan yang berkaitan dengan penggunaan sumber daya publik kepada pemberi mandat (prinsipal). Akuntabilitas adalah kewajiban dari individu atau penguasa yang dipercayakan untuk mengelal sumber daya publik dan yang bersangkutan dengannya kemudian dapat menjawab hal yang menyangkut pertanggungjawabannya. Akuntabilitas terkait erat dengan istrumen untuk kegiatan kontrol terutama dalam hal pencapaian hasil pada pelayanan publik dan menyampaikannya secara transparan kepada masyarakat.Akuntabilitas apabila dikaitkan dengan organisasi pemerintahan, dapat didefinisikan sebagai suatu pemberian informasi atas aktivitas dan kinerja pemerintah kepada pihak-pihak yang berkepentingan

\subsection{Transparansi}

Transparansi atau keterbukaan berarti keputusan yang diambil dan pelaksanaannya dilakukan dengan cara atau mekanisme yang mengikuti aturan atau regulasi yang ditetapkan oleh lembaga. Transparansi juga bisa berarti bahwa informasi yang berkaitan dengan organisasi tersedia secara mudah dan bebas serta bisa diakses oleh mereka yang terkena dampak kebijakan yang dilakukan oleh organisasi tersebut. Kalaupun ada informasi yang tidak boleh diketahui oleh publik, yang sering disebut dengan "rahasia perusahaan", maka harus ada kriteria yang jelas untuk itu. Keterbukaan juga bisa berarti informasi yang cukup berkaitan dengan kinerja lembaga tersedia dan disajikan dalam bentuk atau media yang mudah dipahami masyarakat

\subsection{Indikator Transparansi}

Transparansi merujuk pada ketersediaan informasi pada masyarakat umum dan kejelasan tentang peraturan perundang-undangan dan keputusan pemerintah, dengan indikator sebagai berikut :

a. Akses pada informasi yang akurat dan tepat waktu

b. Penyediaan informasi yang jelas tentang prosedur dan biaya

c. Kemudahan akses informasi

d. Menyusun suatu mekanisme pengaduan jika terjadi pelanggaran

\subsection{Kinerja Pegawai}

kinerja adalah hasil yang dicapai dari yang telah dilakukan, dikerjakan seseorang dalam melaksanakan kerja atau tugas. Kinerja merupakan prestasi kerja atau performance, yaitu hasil kerja selama periode tertentu dibanding dengan berbagai kemungkinan. Kinerja pegawai (prestasi kerja) adalah hasil kerja secara kualitas dan kuantitas yang dicapai oleh seseorang pegawai dalam melaksanakan tugasnya sesuai dengan tanggung jawab yang diberikan kepadanya. Sedangkan, menurut Siswanto Kinerja ialah prestasi yang dicapai oleh seseorang dalam melaksanakan tugas dan pekerjaan yang diberikan kepadanya. Memberikan pengertian bahwa kinerja atau prestasi kerja adalah hasil atau tingkat keberhasilan seseorang secara keseluruhan selama periode tertentu di dalam melaksanakan tugas dibandingkan dengan berbagai kemungkinan, seperti standar hasil kerja, target atau sasaran atau kriteria yang telah ditentukan terlebih dahulu dan disepakati bersama.

\subsection{Penelitian terdahulu}

Penelitian terdahulu yang penulis jadikan sebagai bahan pertimbangan dalam melakukan penelitian pada Dinas Perhubungan Kota Tidore Kepulauan. Penelitian yang dilakukan oleh Made Budi Sastra Wiguna, Gede Adi Yuniartha dan Nyoman Ari Surya Darmawan, tentang Pengaruh pengawasan keuangan daerah, akuntabilitas dan transparansi pengelola keuangan daerah terhadap kinerja pegawai pemerintah daerah kiabupaten buleleng . Tahun 2015 pada pemerintah daerah kabupaten buleleng. 


\section{METODE PENELITIAN}

\subsection{Jenis Penelitian}

Penelitian ini adalah penelitian kuantitatif sebagai metode ilmiah karena telah memenuhi kaidah-kaidah ilmiah yaitu konkrit, objektif, terukur, raisonal, dan sistematis. Analisis data bersifat kuantitatif/statistik dengan tujuan untuk menguji hipotesis yang telah ditetapkan (Sugiyono, 2012: 7).

\subsection{Tempat Penelitian}

Penelitian ini bertempat di Dinas Perhubungan Kota Tidore Kepulauan

\subsection{Sumber Data}

Penelitian memerlukan data baik deskriptif maupun kuantitatif untuk menguji hipotesis. Data tersebut merupakan fakta yang dikumpulkan dalam penelitian terdiri dari dua jenis, yaitu:

1. Data Primer, yaitu data yang diambil secara lansung dari objek penelitian. Cara yang digunakan dalam memperoleh data primer yaitu dengan cara Observasi, wawancara dan kuesioner yang diberikan pada pegawai Dinas Perhubungan Kota Tidore Kepulauan

2. Data Sekunder, yaitu data yang diperoleh secara tidak langsung baik lewat dokumen, buku-buku, literature, penelitian terdahulu, dan internet yang berkaitan dengan penelitian ini

\subsection{Metode Pengumpulan Data}

Dalam penelitian ini digunakan tiga metode pengumpulan data, yaitu:

\subsection{Metode Kuesioner.}

Metode kuesioner adalah metode pengumpulan data dengan cara memberikan atau menyebarkan daftar pertanyaan/pernyataan kepada responden dengan harapan responden memberikan respon atas pertanyaan tersebut.

\subsection{Metode Observasi.}

Metode observasi adalah teknik pengumpulan dta dengan cara melakukan pengamatan dan pencatatan secara sistematik terhadap fenomena yang diselidiki secara langsung ke objek penelitian. Dalam hal ini observasi dilakukan dengan pengamatan langsung terhadap obyek penelitian observasi ini dilakukan untuk memperoleh data yang mendukung hasil kuesioner yang telah disebarkan kepada responden.

\subsection{Metode Analisis Data}

Analisis regresi linier berganda digunakan dalam penelitian ini untuk mengetahui pengaruh pengawasan,akuntabilitas dan transparansi keuangan terhadap kinerja pegawai pada dinas perhubungan kota tidore kepulauan.

Persamaan regresi linear berganda sebagai berikut:

$Y^{\prime}=a+b_{1} X_{1}+b_{2} X_{2}+b_{3} X_{3} \ldots . .+b_{n} X_{n}$

Keterangan:

$\mathrm{Y}^{\prime}=$ Variabel dependen (nilai yang diprediksikan)

$\mathrm{X}_{1}, \mathrm{X}_{2}$ dan $\mathrm{X}_{3}=$ Variabel independen

a $\quad=$ Konstan (nilai $Y^{\prime}$ apabila $X_{1}, X_{2}, X_{3} \ldots \ldots X_{n}=0$ )

$=$ Koefisien regresi (nilai peningkatan ataupun penurunan)

\section{HASIL ANALISIS DAN PEMBAHASAN}

\subsection{Hasil Penelitian}

Berdasarkan kuisioner yang telah dibagikan maka didapat karakteristik responden sebagai berikut: mayoritas responden dalam penelitian ini adalah sebanyak 19 responedn $(63,3 \%)$ dengan jenis kelamin pria, 13 responden $(43,3 \%)$ berusia 31-35 tahun, 27 responden $(90,0 \%)$ berpendidikan Strata 1 (S1) dan 15 responden $(50,0 \%)$ telah bekerja selama 6-10 tahun. 


\section{Uji Validitas Dan Reabilitas}

Semua variabel dalam penelitian ini valid dengan nilai validitas lebih tinggi dari preason correlation minimum yaitu 0,3. Dan berdasarkan hasil uji statistik, seluruh variabel sesuai dengan nilai reabilitas yang lebih tinggi daripada nilai reabilitas minimal Cronbach's Alpha 0,6 $(0>0,6)$.

\section{Analisis Regresi Linier Berganda}

Adapun hasil dari perhitungan Regresi Berganda yaitu:

\section{Tabel 1. Hasil Regresi Berganda}

Coefficients $^{\mathrm{a}}$

\begin{tabular}{|c|c|c|c|c|c|c|c|c|}
\hline & & \multicolumn{2}{|c|}{$\begin{array}{l}\text { Unstandardized } \\
\text { Coefficients }\end{array}$} & \multirow{2}{*}{$\begin{array}{l}\text { Standardized } \\
\text { Coefficients } \\
\text { Beta }\end{array}$} & \multirow{2}{*}{ t } & \multirow[b]{2}{*}{ Sig. } & \multicolumn{2}{|c|}{$\begin{array}{l}\text { Collinearity } \\
\text { Statistics }\end{array}$} \\
\hline \multicolumn{2}{|c|}{ Model } & B & Std. Error & & & & Tolerance & VIF \\
\hline \multirow[t]{4}{*}{1} & (Constant) & 1.838 & .537 & & 3.420 & .002 & & \\
\hline & PENGAWASAN & 1.005 & .199 & 1.208 & 5.049 & .000 & .218 & 4.597 \\
\hline & AKUNTABILITAS & -.547 & .248 & -.532 & -2.206 & .036 & .214 & 4.673 \\
\hline & TRANSPARANSI & .123 & .071 & .198 & 1.735 & .095 & .959 & 1.043 \\
\hline
\end{tabular}

a. Dependent Variable: KINERJA PEGAWAI

Diperoleh persamaan regresi linier berganda sebagai berikut :

$\mathrm{Y}=1.838+1.005 \mathrm{X}_{1}-0.547 \mathrm{X}_{2}+0.123 \mathrm{X}_{3}$

Dari persamaan regresi linier berganda di atas, dapat menginformasikan bahwa :

1. Nilai konstanta sebesar 1.838 dimana nilai itu mempunyai arti bahwa Jika Pengawasan $\left(\mathrm{X}_{1}\right)$, Akuntabilitas $\left(\mathrm{X}_{2}\right)$ dan Transparansi $\left(\mathrm{X}_{3}\right)$ secara serempak atau bersama-sama tidak mengalami perubahan atau sama dengan nol (0) maka besarnya Kinerja Pegawai (Y) sebesar 1.838 satuan.

2. Koefisien regresi Pengawasan Keuangan pada Dinas Perhubungan Kota Tidore Kepulauan $\left(\mathrm{X}_{1}\right)$ sebesar 1.005 yang artinya variabel Pengawasan mempunyai pengaruh positif terhadap variabel Kinerja Pegawai (Y). Nilai koefisien regresi ini mempunyai arti bahwa jika variabel Pengawasan $\left(\mathrm{X}_{1}\right)$ bertambah 1 satuan, maka Kinerja Pegawai (Y) juga akan mengalami kenaikan sebesar 1.005 satuan .

3. Koefisien regresi Akuntabilitas Keuanagn pada Dinas Perhubungan Kota Tidore Kepulauan $\left(\mathrm{X}_{2}\right)$ sebesar 0.547 artinya variabel Akuntabilitas mempunyai pengaruh negatif terrhadap variabel Kinerja Pegawai (Y). Nilai koefisien regresi ini mempunyai arti bahwa jika variabel Akuntabilitas $\left(\mathrm{X}_{2}\right)$ bertambah 1 satuan, maka Kinerja Pegawai (Y) juga akan megalami penurunan sebesar 0.547 satuan.

Koefisien regresi Transparansi Keuangan pada Dinas Perhubungan Kota Tidore Kepulauan $\left(\mathrm{X}_{3}\right)$ sebesar 0,123 yang artinya variabel Transparansi mempunyai pengaruh positif terhadap variabel Kinerja Pegawai (Y). Nilai koefisien regresi ini mempunyai arti bahwa jika variabel Transparansi $\left(\mathrm{X}_{3}\right)$ bertambah 1 satuan, maka Kinerja Pegawai (Y) juga akan mengalami kenaikan sebesar 0,123 satuan.

\section{Uji Hipotesis}

Uji F

Uji $\mathrm{F}$ dilakukan untuk mengetahui pengaruh secara bersama variabel pengawasan, akuntabilitas dan transparansi keuangan terhadap kinerja pegawai pada Dinas Perhubungan 
Kota Tidore Kepuluan, dengan menggunakan uji hipotesis. Uji hipotesis pengaruh secara bersama menggunakan $\mathrm{F}$.

Tabel 2. Hasil Uji F

ANOVA $^{\text {b }}$

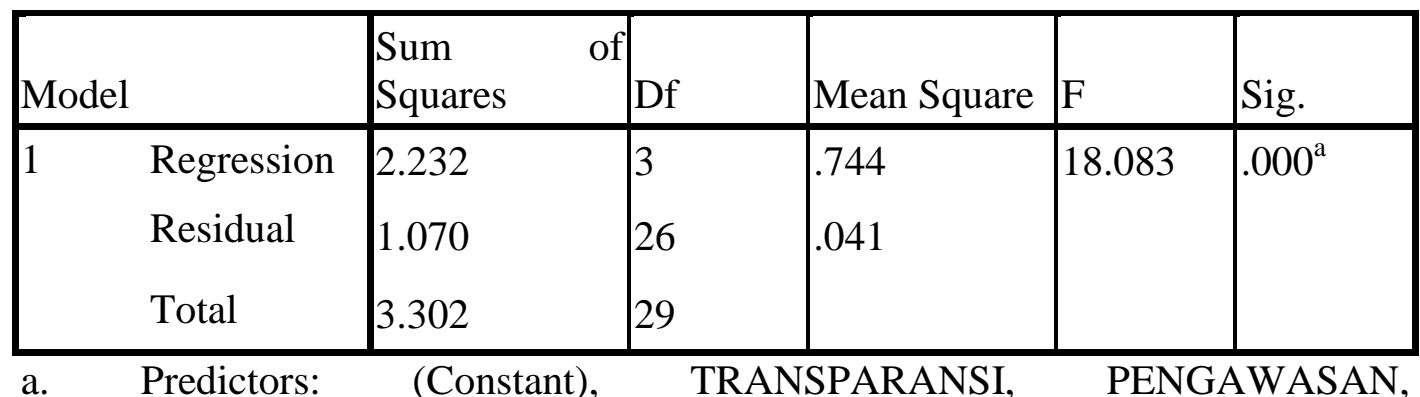

AKUNTABILITAS

b. Dependent Variable: KINERJA PEGAWAI

Hasil Pengujian model regresi untuk keseluruhan variabel menunjukkan nilai $\mathrm{F}$ hitung $=$ 18.083 dengan signifikan $0.000<0.05$ atau kurang dari $5 \%$. Dengan menggunakan batas signifikan 0.05 hasil tersebut didapat bahwa nilai signifikan lebih kecil dari 0.05 dengan arah koefisien positif, dengan demikian diperoleh bahwa hipotesis yang menyatakan bahwa variabel Pengawasan, Akuntabilitas dan Transparansi secara bersama-sama memiliki pengaruh yang signifikan terhadap Kinerja Pegawai diterima.

Uji t

Uji t dilakukan untuk melihat ada/tidaknya Pengaruh Pengawasan, Akuntabilitas dan Transparansi Keuangan Terhadap Kinerja Pegawai pada Dinas Perhubungan Kota Tidore Kepulauan. Uji T dapat dilakukan dengan cara membandingkan angka taraf signifikan hasil perhitungan dengan taraf signifikan $0,05(5 \%)$

Tabel 3. Hasil Uji t

Coefficients $^{\mathrm{a}}$

\begin{tabular}{|c|c|c|c|c|c|c|c|c|}
\hline & & \multicolumn{2}{|c|}{$\begin{array}{l}\text { Unstandardized } \\
\text { Coefficients }\end{array}$} & \multirow{2}{*}{\begin{tabular}{|l}
$\begin{array}{l}\text { Standardized } \\
\text { Coefficients }\end{array}$ \\
Beta
\end{tabular}} & \multirow{2}{*}{ t } & \multirow[b]{2}{*}{ Sig. } & \multicolumn{2}{|c|}{$\begin{array}{l}\text { Collinearity } \\
\text { Statistics }\end{array}$} \\
\hline \multicolumn{2}{|c|}{ Model } & B & Std. Error & & & & Tolerance & VIF \\
\hline \multirow[t]{4}{*}{1} & (Constant) & 1.838 & .537 & & 3.420 & .002 & & \\
\hline & PENGAWASAN & 1.005 & 0.199 & 1.208 & 5.049 & .000 & .218 & 4.597 \\
\hline & AKUNTABILITAS & -.547 & .248 & -.532 & -2.206 & .036 & .214 & 4.673 \\
\hline & TRANSPARANSI & .123 & .071 & .198 & 1.735 & .095 & .959 & 1.043 \\
\hline
\end{tabular}

a. Dependent Variable: KINERJA PEGAWAI

Berdasarkan hasil diperoleh :

1. Variabel Pengawasan, $\mathrm{t}$ hitung $=5.049$ dengan signifikan $0.000<0.05$ maka dapat disimpulkan bahwa Ho ditolak dan Ha diterima atau Pengawasan (X1) berpengaruh signifikan terhadap Kinerja Pegawai (Y). Hasil ini berarti bahwa hipotesis yang menyatakan Pengawasan berpengaruh terhadap Kinerja Pegawai diterima.

2. Variabel Akuntabilitas, $\mathrm{t}$ hitung $=-2.206$ dengan signifikan $0.036<0.05$ maka dapat disimpulkan bahwa Ho ditolak dan Ha diterima atau Akuntabilitas (X2) bepengaruh 
signifikan terhadap Kinerja Pegawai (Y). Hasil ini berarti bahwa hipotesis yang menyatakan Akuntabilitas berpengaruh terhadap Kinerja Pegawai diterima.

3. Variabel Transparansi, $\mathrm{t}$ hitung $=1.735$ dengan signifikan $0.095>0.05$ maka dapat disimpulkan bahwa Ho diterima dan Ha ditolak atau Transparansi (X3) berpengaruh signifikan terhadap Kinerja Pegawai (Y). Hasil ini berarti bahwa hipotesis yang menyatakan Transparansi berpengaruh terhadap Kinerja Pegawai ditolak.

\section{Koefisien Korelasi (R) dan Koefisien Determinasi (R2)}

\section{Tabel 4. Koefisien Korelasi dan Determinasi}

\begin{tabular}{|l|l|l|l|l|}
\hline Model & R & R Square & Adjusted R Square & Std. Error of the Estimate \\
\hline 1 & $.822^{\mathrm{a}}$ & .676 & .639 & .20286 \\
\hline
\end{tabular}

a. Predictors: (Constant), TRANSPARANSI, PENGAWASAN, AKUNTABILITAS

b. Dependent Variable: KINERJA PEGAWAI

\section{Koefisien Korelasi (R)}

Hasil koefisien korelasi atau $\mathrm{R}$ sebesar 0.822 hal ini menunjukkan bahwa hubungan Pengawasan $\left(\mathrm{X}_{1}\right)$, Akuntabilitas $\left(\mathrm{X}_{2}\right)$ dan Transparansi $\left(\mathrm{X}_{3}\right)$ Keuangan terhadap Kinerja pegawai (Y) pada Dinas Perhubungan Kota Tidore Kepulauan, mempunyai hubungan yang positif yaitu sebesar $82.2 \%$ atau bisa dikatakan keeratan hubungannya cukup kuat.

\section{Koefisien Determinasi (R2)}

Hasil Koefisien Determinasi atau R square $\left(\mathrm{r}^{2}\right)$ adalah 0.676 yang menunjukan bahwa variasi Kinerja Pegawai pada Dinas Perhubungan Kota Tidore Kepulauan (Y) dapat dijelaskan oleh variasi dari Pengawasan Keuangan pada Dinas Perhubungan Kota Tidore Kepulauan $\left(\mathrm{X}_{1}\right)$, Akuntabilitas Keuangan pada Dinas Perhubungan Kota Tidore Kepulauan $\left(\mathrm{X}_{2}\right)$ dan Transparansi Keuangan pada Dinas Perhubungan Kota Tidore Kepulauan $\left(\mathrm{X}_{3}\right)$ $67.6 \%$, sementara sisanya sebesar $32.4 \%$ dijelaskan oleh variabel-variabel lain yang tidak diteliti dalam penelitian ini.

\subsection{Pembahasan}

Berdasarkan hasil Uji Statistik uji $\mathrm{F}$ yang telah dilakukan oleh peneliti dapat dijelaskan bahwa Pengawasan, Akuntabilitas dan Transparansi Keuangan berpengaruh signifikan terhadap Kinerja Pegawai dikarenakan tingkat signifikan yang ditunjukkan lebih kecil dari 0.05 yaitu 0.000 . Hal ini berarti bahwa ada hubungan yang signifikan secara simultan atau bersama-sama dari Pengawasan (X1), Akuntabilitas (X2) dan Transparansi Keuangan (X3) terhadap Kinerja Pegawai (Y). Pengaruh model peneltian ini dari variabel Pengawasan, Akuntabilitas dan Transparansi keuangan berdasarkan uji korelasi (R) sebesar 82.2\%. Sedangkan berdasarkan uji determinasi ) adalah sebesar $67.6 \%$ dan sisanya $32.4 \%$ dipengaruhi oleh variabel di luar penelitian ini. Ini mengartikan bahwa peran Pengawasan, Akuntabilitas dan Transparansi Keuangan mempengaruhi Kinerja Pegawai pada Dinas Perhubungan Kota Tidore Kepulauan.

\section{KESIMPULAN DAN SARAN}

\subsection{Kesimpulan}

1. Berdasarkan hasil uji hipotesis ditemukan bahwa Pengawasan Keuangan memiliki pengaruh positif dan signifikan terhadap Kinerja Pegawai pada Dinas Perhubungan Kota Tidore Kepulauan. 
2. Berdasarkan hasil hipotesis ditemukan bahwa Akuntabilitas Keuangan memliki pengaruh positif dan signifikan terhdap Kinerja Pegawai pada Dinas Perhubungan Kota Tidore Kepulauan.

3. Berdasarkan hasil hipotesis ditemukan bahwa Transparansi Keuangan memliki pengaruh negatif dan tidak signifikan terhadap Kinerja Pegawai pada Dinas Perhubungan Kota Tidore Kepulauan.

4. Berdasarkan hasil uji hipotesis ditemukan bahwa Pengawasan, Akuntabilitas keuangan memiliki pengaruh positif atau signifikan terhadap Kinerja Pegawai sedangkan Transparansi Keuangan memiliki pengaruh negatif atau tidak signifikan terhadap Kinerja Pegawai pada Dinas Perhubungan Kota Tidore Kepulauan. Maka hipotesis yang menyatakan bahwa Transparansi Keuangan diduga berpengaruh positif terhadap Kinerja Pegawai ditolak.

\subsection{Saran}

1. Variabel Pengawasan Keuangan memberikan pengaruh yang positif terhadap Kinerja Pegawai pada Dinas Perhubungan,Kota Tidore Kepulauan dan sebaiknya pada Dinas Perhubungan Kota Tidore Kepulauan mempertahankan dan meningkatkan Pengawasan Keuangan agar proses dalam menetapkan ukuran kinerja dan pengambilan tindakan yang dapat mendukung pencapaian hasil yang diharapkan sesuai dengan kinerja yang telah di tetapkan.

2. Variabel Akuntabilitas Keuangan memberikan pengaruh yang positif terhadap Kinerja Pegawai pada Dinas Perhubungan,Kota Tidore Kepulauan dan sebaiknya pada Dinas Perhubungan Kota Tidore Kepulauan mempertahankan dan meningkatkan Akuntabilitas Keuangan di karenakn Akuntabilitas atau pertanggungjawaban atau pertangungjelaskan merupakan sebuah konsep etika yang dekat dengan administrasi pemerintahan jika Akuntabilitas pada Dinas Perhubungan Kota tidore Kepulauan di tingkatkan maka administrasi pada Dinas Perhubungan kota Tidore Kepulauan Juga semakin baik.

\section{DAFTAR PUSTAKA}

Arifiyadi, Teguh. (2008). Konsep tentang akuntabilitas dan implementasinya di indonesia. September 10, 2009.

Hasibuan, \& Malayu S. P. (2009) . Manajemen : Dasar, Pengertian, Dan Masalah : Edisi Revisi. Bumi Aksara : Jakarta.

Husein, U. (2011)a. Metode Penelitian Untuk Skripsi dan Tesis Bisnis : Edisi 11. PT Raja Grafindo Persada : Jakarta.

Husein, U. (2011)b. Metode Penelitian Untuk Skripsi dan Tesis Bisnis : Edisi 11. PT Raja Grafindo Persada : Jakarta.

Mahmudi. (2016). Analisis Lapoan Keuangan Pemerintah Daerah : Edisi Ke-3. UPP STIM YKPN : yogyakarta.

Mangkunegara, A. A. Anwar Prabu. (2009). Manajemen Sumber Daya Manusia: Pt. Remaja Rosdakarta : Bandumg.

Mardiasmo.(2016). Perpajakan-Edisi Terbaru 2016. Penerbit Andi. Yogyakarta.

Sandy Martha, Muhammad. (2015). "Karakteristik Pekerjaan dan Kinerja Dosen Luar Biasa UIN Sunan Gunung Djati Bandung: Komitmen Organisasi Sebagai Variabel Moderating". Tesis di Universitas Widayatama Bandung.

Siswandi, \& Imam, I. (2009) . Aplikasi Manajemen Perusahaan : Edisi Ke-2. Mitra Wicana Media : Jakarta.

Sugiyono. (2012). Metode Penelitian Kuantitatif Kualitatif dan R\&D : Alfabeta : Bandung. 